\title{
Effect of inhaled hypertonic saline on hospital admission rate in children with viral bronchiolitis: a randomized trial
}

\author{
Brian A. Kuzik, MD, MSc; ${ }^{*}$ Michael P. Flavin, MB; ${ }^{\dagger}$ Steven Kent, MD; ${ }^{\ddagger}$ David Zielinski, MD; ${ }^{\S}$ \\ Charisse W. Kwan, MD; ${ }^{\dagger}$ Adetayo Adeleye, MD; ${ }^{\dagger}$ Bjorn C. Vegsund, MD; ${ }^{\ddagger}$ Carlo Rossi, $\mathrm{MDCM}^{\ddagger}$
}

\section{ABSTRACT}

Objective: We sought to determine whether inhaled $3 \%$ hypertonic saline (HS) reduces admission to hospital in ambulatory children with moderately severe viral bronchiolitis. Secondary objectives compared changes in respiratory scores before and after treatment and assessed the need for unscheduled medical intervention within 7 days.

Methods: Children under the age of 2 years presenting with moderately severe viral bronchiolitis to the emergency department of 4 general hospitals from November 2008 to March 2009 were randomly assigned to receive 3 consecutive 4-mL doses of nebulized 3\% HS (treatment group) or $0.9 \%$ normal saline (NS; control group) in a double blind fashion, each coadministered with $1 \mathrm{mg}$ salbutamol. Outcome measures included the difference in hospital admission rate and changes in respiratory distress scores.

Results: A total of 81 children (mean age 8.9 mo, range $0.7-$ $22 \mathrm{mo}$ ) were assessed over 88 visits on an intention-to-treat basis. No statistically significant differences were found between treatment groups. Children in the HS group had a nonsignificant trend toward greater improvement compared with NS controls with a same-day admission rate of $18 \%$ (95\% confidence interval $[\mathrm{Cl}]$ 9\%-32\%) versus $27 \%(95 \% \mathrm{Cl}$ $16 \%-42 \%)$, respectively. Respiratory Assessment Change Scores (RACS) favoured the HS group over NS controls (mean RACS 4.7 [95\% Cl 3.6-5.8] v. 3.7 [95\% Cl 2.5-4.9], respectively), although the $\mathrm{Cls}$ overlap and these differences were not statistically significant.

Conclusion: The short-term use of nebulized 3\% HS did not result in any statistically significant benefits, although a nonsignificant trend toward a decrease in admission rate and improvement in respiratory distress was found. A larger study would be required to determine whether these trends arise from a clinically relevant treatment effect.
Keywords: randomized, asthma, wheezing, respiratory syncytial virus, respiratory infection, salbutamol, albuterol, hypertonic saline, bronchiolitis

Registration: ClinicalTrials.gov NCT00677729, May 2008.

\section{RÉSUMÉ}

Objectif : Nous avons cherché à déterminer si la nébulisation d'une solution saline hypertonique à $3 \%(\mathrm{SH})$ réduit les hospitalisations chez les nourrissons présentant une bronchiolite virale modérément sévère. Les objectifs secondaires portaient sur la comparaison des changements dans les scores de mesure de la fonction respiratoire pré- et post-traitement et l'évaluation de la nécessité d'une intervention médicale non prévue dans les 7 jours suivants.

Méthodes : Cette étude à double insu portait sur des nourrissons de moins de 2 ans ayant une bronchiolite virale modérément sévère et s'étant présentés à l'urgence de 4 hôpitaux généraux entre novembre 2008 et mars 2009. Ils ont été assignés au hasard à recevoir 3 doses consécutives de $4 \mathrm{~mL}$ de $\mathrm{SH}$ à $3 \%$ par nébulisation (groupe de traitement) ou 3 doses de solution physiologique (SP) à 0,9\% (groupe témoin). Les deux groupes ont aussi reçu $1 \mathrm{mg}$ de salbutamol. Les mesures des résultats étaient la différence dans les taux d'hospitalisation et les changements dans les scores de mesure de la détresse respiratoire.

Résultats : Au total, 81 nourrissons (âge moyen de 8,9 mois, fourchette de 0,7 à 22 mois) ont été évalués lors de plus de 88 visites avec intention de traiter. Aucune différence statistiquement significative n'a été constatée entre les groupes traités. Les enfants du groupe HS avaient une tendance non significative vers une plus grande amélioration par rapport au groupe témoin SP. Ils avaient respectivement des taux d'hospitalisation le jour même de $18 \%$ (intervalle de confiance à $95 \%$ [IC], de 9 à $32 \%$ ) contre $27 \%$ (IC à $95 \%$, de 16 à

From the *Department of Paediatrics, Royal Victoria Hospital, Barrie, Ont., the tDepartment of Pediatrics, Queen's University, Kingston General Hospital, Kingston, Ont., the ¥Department of Pediatrics, University of British Columbia, Victoria General Hospital, Victoria, BC, and the §Department of Pediatrics, Hotel Dieu Hospital, Queen's University, Kingston, Ont.

Submitted Oct. 23, 2009; Revised Jan. 19, 2010, Feb. 11, 2010; Accepted Mar. 8, 2010

This article has been peer reviewed.

CJEM 2010;12(6):477-84 
$42 \%)$. Le score de modification de la fonction respiratoire (SMFR) favorise le groupe HS plutôt que le groupe témoin SP (SMFR de 4,7 [IC à $95 \%$, de 3,6 à 5,8] contre 3,7 [IC à $95 \%$, de 2,5 à 4,9], respectivement), bien que les IC se chevauchent et que ces différences ne soient pas statistiquement significatives. Conclusion : L'utilisation à court terme d'une solution saline hypertonique à $3 \%$ par nébulisation n'a pas donné lieu à des avantages statistiquement significatifs, même si une tendance non significative vers une diminution des taux d'hospitalisation et une amélioration de la fonction respiratoire a été observée. II faudrait réaliser une étude plus vaste pour déterminer si ces tendances résultent de l'effet cliniquement pertinent du traitement.

\section{INTRODUCTION}

Viral bronchiolitis is the most common form of lower respiratory infection in children under the age of 12 months and accounts for $17 \%$ of infant admissions to hospital at an estimated annual cost of more than \$500 million in the United States. ${ }^{1-3}$ Respiratory syncytial virus accounts for the majority of cases, although human metapneumovirus, adenovirus, rhinovirus, parainfluenza and influenza viruses can also cause bronchiolitis. ${ }^{1-3}$ Bronchiolitis is a self-limiting infection characterized by widespread airway plugging from sloughed epithelium, mucus and edema. ${ }^{4-6}$ Symptoms typically result in children being brought to the emergency department (ED) on day 3 to 5 of their illness, at which point up to $40 \%$ will require hospital admission. ${ }^{7,8}$ Until recently, no short- or long-term treatment has been proven to be effective, and therapy remains supportive with the administration of oxygen, fluids and mechanical ventilation as required..$^{910}$

Several recent reports have found that inhalation of nebulized 3\% hypertonic saline (HS) improves both immediate and long-term clearance of small airways in children with viral bronchiolitis. ${ }^{711-13}$ The exact mechanism of action is unknown, but HS is thought to facilitate removal of inspissated mucus through osmotic hydration, disruption of mucus strand cross-linking and reduction of mucosal edema. ${ }^{14,15}$ In all studies to date, HS has been coadministered with a bronchodilator to reduce the theoretical risk of HS-induced bronchospasm, and any beneficial effects have been attributed to the HS alone. In a study of outpatients with mild bronchiolitis, the inhalation of a single nebulized 2-mL dose of $3 \%$ HS coadministered with a bronchodilator was superior to saline controls in the reduction of symptom scores immediately after treatment; however, when HS was continued 3 times daily, the admission rate was unchanged. ${ }^{11}$ In admitted and presumably sicker infants with bronchiolitis, higher dose therapy with $4 \mathrm{~mL} \mathrm{HS}$ and a bronchodilator given a mean of 9 times daily has been found to reduce length of stay. ${ }^{12}$

The use of nebulized 3\% HS in children admitted with moderately severe viral bronchiolitis is a safe and effective therapy, although the optimum dose is unknown. The purpose of this study was to determine whether inhaled 3\% HS, administered more intensively than previously described, reduces hospital admission in ambulatory children with moderately severe viral bronchiolitis. Secondary objectives compared changes in respiratory scores before and after treatment, and assessed the need for unscheduled medical intervention within 7 days.

\section{METHODS}

\section{Setting}

The study was conducted at 4 Canadian general hospitals with mixed adult-pediatric emergency services: Royal Victoria Hospital (Barrie, Ont.), Kingston General Hospital (Kingston, Ont.), Hotel Dieu Hospital (Kingston, Ont.) and Victoria General Hospital (Victoria, $\mathrm{BC})$. Patients were assessed and treated in the $\mathrm{ED}$ (all hospitals) or in the acute treatment area of the Children's Outpatient Centre (Hotel Dieu Hospital).

\section{Patients}

Children aged up to 24 months presenting with moderately severe viral bronchiolitis were eligible for inclusion in the study. Inclusion criteria required history of a preceding viral upper respiratory tract infection, the presence of wheezing or crackles on chest auscultation, and an oxygen saturation level of $94 \%$ or less on room air or moderate respiratory distress as measured by a Respiratory Distress Assessment Instrument (RDAI) score of 4 or greater. An RDAI score involves assigning a numerical value to 6 separate assessments; the sum of these scores provides an RDAI score ranging from 0 to 17 , with increasing scores indicating increasing respiratory distress (Table 1). ${ }^{16}$

Exclusion criteria were any of the following: immunodeficiency, Down syndrome, neurologic or metabolic disease, chronic cardiopulmonary disease other than recur- 
rent wheezing, severe illness at presentation (respiratory rate $>80$ breaths $/ \mathrm{min}$, oxygen saturation $<88 \%$ on room air or need for assisted ventilation), prematurity (gestational age $\leq 34 \mathrm{wk}$ ) or use of inhaled HS within the previous 12 hours.

\section{Study design}

The flow of patients through the study is shown in Figure 1. Children aged up to 24 months with apparent bronchiolitis who presented to study locations between 8:00 am and midnight from Nov. 1, 2008, to Mar. 31,
2009, were assessed for enrolment by one of the authors or a research assistant. When inclusion and exclusion criteria were satisfied, informed consent was sought and participants were allocated to receive a nebulized solution containing $1 \mathrm{mg}$ salbutamol (albuterol) plus $4 \mathrm{~mL}$ of $3 \% \mathrm{HS}$ (study group) or $1 \mathrm{mg}$ salbutamol plus $4 \mathrm{~mL}$ of $0.9 \%$ normal saline (NS; control group). Each participant remained on the same allocation throughout the protocol and received 3 consecutive 4-mL doses of the assigned solution with salbutamol over a 1-hour period. All inhaled therapies were delivered from a standard oxygen-driven hospital nebulizer through a tight-fitting

\begin{tabular}{|c|c|c|c|c|c|c|}
\hline \multirow[b]{2}{*}{ Symptom } & \multicolumn{5}{|c|}{ Score } & \multirow{2}{*}{$\begin{array}{l}\text { Maximum } \\
\text { score }\end{array}$} \\
\hline & 0 & 1 & 2 & 3 & 4 & \\
\hline \multicolumn{7}{|l|}{ Wheeze/crackles } \\
\hline During expiration & None & End only & $1 / 2$ Phase & $3 / 4$ Phase & Throughout & 4 \\
\hline During inspiration & None & Partial & Throughout & - & - & 2 \\
\hline Lung fields involved & None & $<2$ of 4 & $>3$ of 4 & - & - & 2 \\
\hline \multicolumn{7}{|l|}{ Retractions } \\
\hline Supraclavicular & None & Mild & Moderate & Marked & - & 3 \\
\hline Intercostal & None & Mild & Moderate & Marked & - & 3 \\
\hline Subcostal & None & Mild & Moderate & Marked & - & 3 \\
\hline Total & & & & & & 17 \\
\hline
\end{tabular}

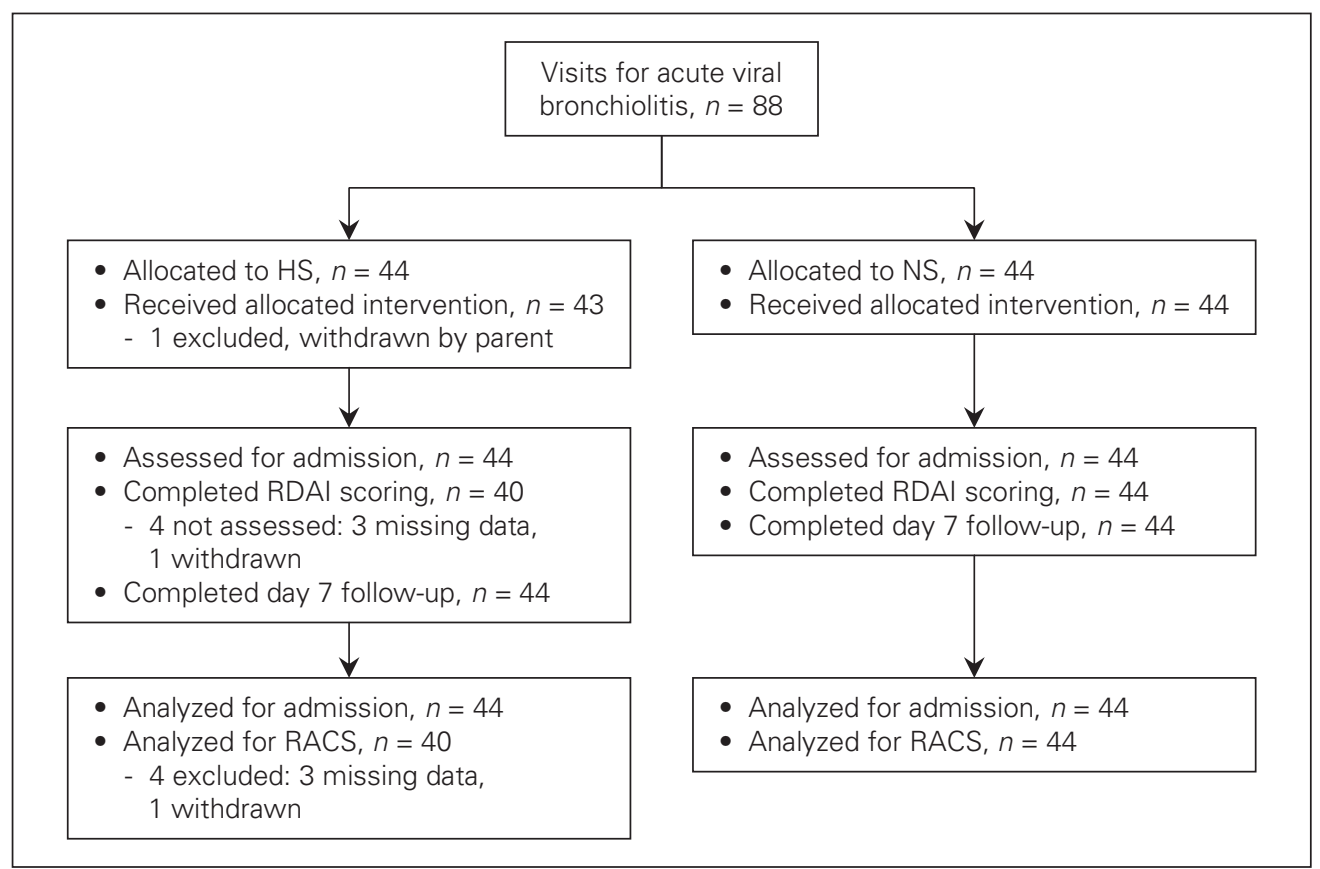

Fig. 1. Flow chart showing assignment of patients to treatment groups, follow-up and analysis for 88 visits for acute viral bronchiolitis. HS = hypertonic saline; NS = normal saline; RACS = Respiratory Assessment Change Score; RDAl = Respiratory Distress Assessment Instrument. 
face mask or head box, whichever was better tolerated. An RDAI score on room air was obtained by one of the authors or a research assistant immediately before the first treatment and after a 1-hour observation period following the third treatment. Children did not receive further therapy other than supplemental oxygen (if necessary) during the observation period. After the second RDAI score was obtained, the admission decision was made by the emergency physician, who was aware of the study but was unaware of the treatment allocation and RDAI values.

Study solutions were prepared in advance by a research pharmacist at each study site and were randomly placed in blocks of 6 using a Web-based program. Normal saline and HS study solutions were identical in appearance and odour and were labelled with sequential numbers. The investigator responsible for recruiting the patient and supervising the protocol obtained the next available study solution. The identity of the study solution was known only to the research pharmacists and was not revealed until after completion of the study.

\section{Measurement of treatment effect}

The decision to admit to hospital was left to the discretion of the attending emergency physician; all health care providers were unaware of the treatment allocations and the RDAI scores.

The change in respiratory distress after completion of the study protocol was determined by calculating the Respiratory Assessment Change Score (RACS). ${ }^{16}$ A positive RACS is a numerical estimate of the improvement in respiratory distress between 2 points in time, whereas a negative RACS reflects a worsening. The RACS is calculated by combining 2 values: the difference between the RDAI score obtained before and after treatment (RDAI score before minus RDAI score after treatment), plus a value of +1 for each $10 \%$ improvement (decrease) in the posttreatment respiratory rate or a value of -1 for each $10 \%$ worsening (increase) in respiratory rate. The respiratory rates were determined in settled children by the investigator at the time of RDAI scoring. Clinically relevant improvement has been previously defined as an RACS of at least $+4 .{ }^{16}$

After 7 days, a research assistant, unaware of study group allocation, contacted the parents by telephone to assess whether children had required further unscheduled medical visits or hospital admission for respiratory illness following the index visit.

\section{Ethics}

The study was approved by the ethics and human research committees of each of the participating hospitals. Informed written consent was obtained from a parent of each child before enrolment.

\section{Statistical analysis}

Sample size was calculated on the basis of the averaged current admission rate of approximately $40 \%$ at the 4 hospitals, and an anticipated $50 \%$ reduction with short-term intensive treatment with HS. Using an $\alpha$ of 0.05 and a 2 -tailed test, this required a sample size of 85 per arm, which we anticipated could be obtained during a single bronchiolitis season in our combined study centres.

Data were entered into an Excel file developed for this study, and imported into SPSS (version 17.0 for Windows) for statistical analysis. Respiratory Assessment Change Scores were graphed to assess the distribution. Skewedness and kurtosis were also evaluated for the RDAI scores and RACS. Following descriptive analyses for the entire sample, the HS and NS groups were compared using independent samples $t$ tests for continuous data such as age, RDAI score and RACS, and Fisher exact test or Pearson $\chi^{2}$ test as appropriate for categorical data such as sex and previous history of wheezing. Subgroup analyses of the RACS were completed for previously chosen subgroups (age $\leq 12 \mathrm{mov}$. $>12 \mathrm{mo}$, and previous history of wheezing) to assess whether any differential benefit existed.

\section{RESULTS}

\section{Study population}

Data were obtained on 88 episodes of acute viral bronchiolitis occurring in 81 children enrolled from Nov. 1, 2008, to Mar. 31, 2009. The mean age of study participants was 8.9 months (range $0.7-22 \mathrm{mo}$ ). One participant was withdrawn at parental request and an RACS could not be determined in an additional 3 children because of missing data. All 4 of these participants were included in the final analysis, in keeping with an intentionto-treat approach.

The RDAI scores before and after treatment were normally distributed, as were the RACS. Calculation of skewedness and kurtosis for the 3 scores indicated that all fell within the expected range of chance fluctuations, and as a result parametric statistics were used for all analyses. 
The HS and NS groups were comparable at baseline (Table 2), and patients typically presented on day 4 of their illness (range 1-21 d) with a slightly decreased mean oxygen saturation of $96 \%$ (range $88 \%-100 \%$ ) and moderate respiratory distress with a mean RDAI score of 8.6 out of 17 (range 4-14). Of participants who had nasopharyngeal sampling for viral identification, $47 \%$ were positive for respiratory syncytial virus. Forty-three percent of participants had a previous history of wheezing.

\section{Adverse effects}

All children tolerated therapy without apparent adverse effects, and none were withdrawn by medical staff because of clinical deterioration. One 11-month-old girl in the HS group was withdrawn by her parent before completion of the first inhalation treatment because of excessive crying. This event was not considered to be clinically significant by the attending ED staff, and the infant was eventually discharged from the ED without incident after receiving standard therapy.

\section{Response to therapy}

Children receiving therapy with HS did not show any statistically significant benefit compared with NS controls, although there was a nonsignificant trend toward a reduced same-day admission rate (18\% [95\% CI 9\%$32 \%$ ] v. $27 \%$ [95\% CI $16 \%-42 \%$ ], respectively) and improved respiratory distress (RACS 4.7 [95\% CI 3.6-5.8] v. 3.7 [95\% CI 2.5-4.9], respectively) (Table 3). Although patients in both the treatment and control groups improved, only children receiving HS consistently achieved a clinically relevant mean RACS of at least +4 ; this benefit appeared to be independent of age over 12 months or a previous history of wheezing (Fig. 2). A secondary analysis with the elimination of 7 participants recruited more than once did not significantly alter the results.

Subsequent morbidity based on 7-day follow-up was similar between the treatment groups (Table 3).

\section{DISCUSSION}

This prospective, randomized, double-blind, controlled, multicentre study reports the effects of inhaled 3\% HS used in a more intensive manner than described previously in children with moderately severe viral bronchiolitis. When compared with NS controls, a total dose of $12 \mathrm{~mL}$ HS nebulized over approximately 1 hour did not result in a statistically significant improvement in measured outcomes, although a trend toward a decrease in same-day admission rate and improvement in respiratory distress scores was found.

All children appeared to tolerate the treatment well. This was expected, as it has previously been shown that $4 \mathrm{~mL}$ of $3 \%$ HS nebulized on average 9 times per day is safe and well-tolerated. ${ }^{7}$ We did not test for posttreatment hypernatremia, as prior studies have shown that the nebulization methods we used are associated with a mean lung deposition of $2.5 \%$ and a maximum $23 \%$ systemic absorption through the upper respiratory tract and swallowing, ${ }^{17} 12 \mathrm{~mL}$ of nebulized 3\% HS would there-

\begin{tabular}{|c|c|c|c|}
\hline \multirow[b]{2}{*}{ Characteristic } & \multicolumn{2}{|c|}{ No. $(\%)$ of cases* } & \multirow[b]{2}{*}{$p$ value } \\
\hline & $\begin{array}{c}\text { Normal saline, } \\
\quad n=44^{*}\end{array}$ & $\begin{array}{c}\text { Hypertonic } \\
\text { saline, } n=44^{*}\end{array}$ & \\
\hline Mean (SD) age, mo & $9.2(5.2)$ & $8.6(5.6)$ & 0.60 \\
\hline Male sex, \% & 82 & 73 & 0.31 \\
\hline Mean (SD) RDAI score & $8.7(2.7)$ & $8.5(2.6)$ & 0.66 \\
\hline Mean (SD) oxygen saturation on room air, \% & $95.7(3.0)$ & $95.9(2.2)$ & 0.73 \\
\hline Mean (SD) duration of illness before presentation, $d$ & $4.6(3.9)$ & $3.4(1.6)$ & 0.06 \\
\hline Previous history of wheezing & $23(52)$ & $15(34)$ & 0.09 \\
\hline History of bronchodilator use & $18(41)$ & $19(43)$ & 0.83 \\
\hline Maternal smoking during pregnancy & $10(23)$ & $5(11)$ & 0.16 \\
\hline Received steroids this illness before study entry & $10(23)$ & $5(11)$ & 0.16 \\
\hline Tested for RSV & $21(48)$ & $24(55)$ & 0.52 \\
\hline RSV positive & $11 / 21(52)$ & $10 / 24(42)$ & 0.47 \\
\hline
\end{tabular}


fore be expected to deliver a maximum systemic dose of only $1.4 \mathrm{mmol} / \mathrm{L}$ of sodium. In addition, the total dose of salbutamol administered $(3 \mathrm{mg})$ was similar or less than doses shown to be well-tolerated in infants. ${ }^{18,19} \mathrm{Sim}-$ ilar to all other studies, we coadministered a bronchodilator solely to reduce the theoretical risk of HS-induced bronchospasm,,$^{20}$ although it is unclear whether this was necessary. ${ }^{21}$

Nebulized HS, coadministered with a bronchodilator over a number of days, is an effective treatment for viral bronchiolitis in admitted children, although the optimum volume, strength and dosing frequency are unknown. ${ }^{7,12,13}$ The possible immediate benefit of using HS in outpatients is less clear. Although a recent review has shown that, when compared with matching controls who received NS administered with a bronchodilator, a single 2- to 4-mL dose of $3 \%$ HS with epinephrine produces an immediate reduction of clinical scores of $11 \%-$ $20 \%,{ }^{13}$ earlier $^{11}$ and subsequent ${ }^{22,23}$ studies on the use of HS in outpatients with bronchiolitis have not confirmed this. For example, in 2002, Sarrell and colleagues $^{11}$ studied low-dose $3 \%$ HS $(2 \mathrm{~mL}$ with terbutaline) 3 times daily over 5 days and demonstrated short-term improvements in outpatient children with relatively mild bronchiolitis, but found no reduction in their already low admission rate. Subsequent to the completion of our study, a similar but smaller ED-based study by Grewal and colleagues ${ }^{22}$ in 2009 found that low-dose nebulized $3 \%$ HS ( 1 or 2 doses of $2.5 \mathrm{~mL}$ with epinephrine over $2 \mathrm{~h}$ ) in infants with moderately severe bronchiolitis (mean RDAI score at baseline 8.9) failed to improve clinical scores but did show a trend toward a decreased admission rate when compared with NS controls. In comparison, the participants in our study had a similar illness severity at baseline (mean RDAI score 8.6) but still showed only a nonsignificant trend toward improved respiratory scores and reduced admission in the HS group, despite having received

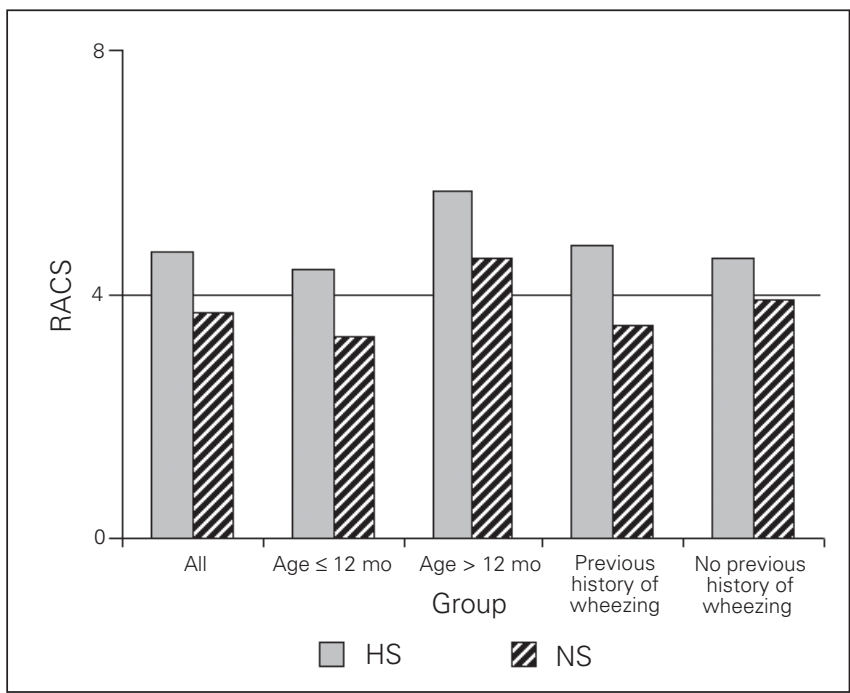

Fig. 2. Mean Respiratory Assessment Change Score (RACS) in 81 children receiving hypertonic saline (HS) and normal saline (NS) for 88 episodes of acute viral bronchiolitis, by age and previous history of wheezing.

\begin{tabular}{|c|c|c|c|}
\hline Variable and group & Normal saline & Hypertonic saline & $p$ value \\
\hline \multicolumn{4}{|l|}{ Mean (SD) RACS [total no.] } \\
\hline All, $n=84^{*}$ & 3.7 (4.0) $[44]$ & 4.7 (3.5) $[40]^{*}$ & 0.24 \\
\hline Age $\leq 1 \mathrm{yr}, n=60$ & 3.3 (3.6) [30] & 4.4 (3.6) $[30]$ & 0.27 \\
\hline Age $>1 \mathrm{yr}, n=24$ & $4.6 \quad(4.8)[14]$ & 5.7 (2.9) [10] & 0.53 \\
\hline Previous history of wheezing, $n=38$ & 3.5 (4.3) [23] & $4.8 \quad(3.7)[15]$ & 0.35 \\
\hline No previous history of wheezing, $n=46$ & 3.9 (3.7) [21] & $4.6 \quad(3.4) \quad[25]$ & 0.52 \\
\hline \multicolumn{4}{|l|}{ Admitted at initial presentation only, no. (\%) } \\
\hline All, $n=88$ & $12 / 44(27)$ & 8/44 (18) & 0.31 \\
\hline Age $\leq 1 \mathrm{yr}, n=64$ & $7 / 30(23)$ & $7 / 34(21)$ & 0.79 \\
\hline Age $>1 \mathrm{yr}, n=24$ & $5 / 14(36)$ & $1 / 10(10)$ & 0.34 \\
\hline Previous history of wheezing, $n=38$ & $4 / 23(17)$ & $3 / 15(20)$ & 0.84 \\
\hline No previous history of wheezing, $n=50$ & $8 / 21(38)$ & $5 / 29(17)$ & 0.10 \\
\hline \multicolumn{4}{|l|}{ Admitted within 7 days after initial presentation } \\
\hline Subset not initially admitted, $n=67$ & 4/31 (13) & $3 / 36 \quad(8)$ & 0.70 \\
\hline \multicolumn{4}{|c|}{ Unscheduled physician visits within 7 days of presentation } \\
\hline Subset not initially admitted, $n=67$ & $13 / 31(42)$ & $13 / 36(36)$ & 0.63 \\
\hline
\end{tabular}


more intensive therapy (total $12 \mathrm{~mL} \mathrm{3 \%} \mathrm{HS} \mathrm{over} 1 \mathrm{~h}$ ). Unlike Grewal and colleagues, ${ }^{22}$ we included children with a previous history of wheezing, but this did not appear to influence results and is of unclear significance, as discussed below.

In a 2010 ED-based study, Anil and colleagues ${ }^{23}$ used moderate-dose $3 \%$ HS (2 doses of $4 \mathrm{~mL}$ with bronchodilator over approximately $1 \mathrm{~h}$ ) in children with mild bronchiolitis and failed to show any significant improvement in clinical scores after 2 hours when compared with NS controls. Of note, the children studied had very low (mild) clinical scores at baseline and after 30 minutes, as well as a low $1 \%$ overall admission rate, indicating the presence of much milder bronchiolitis than in our participants. The authors concluded that their findings should not be extrapolated to moderateto-severe bronchiolitis and could not be interpreted as a lack of response to HS.

Our study had a number of limitations. A priori sample size calculations had indicated that 85 patients would be required in each arm to attain statistical significance, but, despite our projections, we had insufficient recruitment during the single bronchiolitis season during which the study took place. Regrettably, this made the study significantly underpowered, although the improvement in all outcome measures seen in the HS group is promising. In addition, although the patients enrolled were very similar to those in other larger ED-based bronchiolitis studies, ${ }^{8,24}$ our study differed from others by the inclusion of slightly older children (up to age $24 \mathrm{mo}$ ) and children with a previous history of wheezing. Viral bronchiolitis, however, does not have a universally accepted definition and has been described as an episode of viral-induced wheezing restricted to children under the age of 6 months, ${ }^{10}$ under 12 months $^{8,24}$ or up to 2 years. ${ }^{9}$ Presumably to distinguish it from other conditions that cause wheezing, some prior studies of bronchiolitis excluded children with a previous history of wheezing ${ }^{18,25,26}$ whereas others did not. ${ }^{27,28}$ There is no compelling evidence, however, to justify treating the initial episode of viral-induced wheezing any differently from subsequent episodes within the first 2 years of life; indeed, there is no evidence that it is practical or reliable to identify a previous history of wheezing based on parental reporting. Recent authors have raised this point and simply categorize wheezing in infancy according to its trigger (viral, allergic or other) and note its likelihood to be the harbinger of future asthma with no special significance given to whether a presentation is a first or subsequent episode. ${ }^{29,30}$ Mansbach and colleagues, ${ }^{28}$ in a large multicentre study of children under 24 months old with bronchiolitis, found that neither a previous history of wheezing nor age over or under 12 months affected the need for admission. Similarly, we found that age over 12 months and/or a previous history of wheezing did not appear to influence our findings, although our small numbers precluded a robust subgroup analysis.

We believe the possible role of intensive therapy with inhaled HS in reducing hospital admission in children with viral bronchiolitis or perhaps other recurrent wheezing conditions is an important question that warrants further study. We suggest that future large-scale studies should involve treatment arms using HS with and without bronchodilator as well as consideration of using higher tonicity solutions such as the 7\% HS currently used in treatment of cystic fibrosis. ${ }^{31}$ The probable need for multiple study sites will likely require the use of strict predetermined admission criteria to ensure the reliability and validity of this very important outcome measure across differerent locations.

\section{CONCLUSION}

The short-term use of nebulized 3\% HS did not result in any statistically significant benefits, although a nonsignificant trend toward a decrease in hospital admission and improvement in respiratory distress was found. A larger study would be required to determine whether these trends arise from a clinically relevant treatment effect.

Acknowledgements: The authors gratefully acknowledge the essential assistance of Sue Jones and her team in the Respiratory Services Division of the Royal Victoria Hospital, as well as the financial assistance of the physicians of Ontario through the Physicians' Services Incorporated Foundation.

Competing interests: None declared.

Funding: Funding was provided by the Physicians' Services Incorporated Foundation. The Physicians' Services Incorporated Foundation did not participate in the preparation of this manuscript. The authors did not receive any direct payment for the preparation of this manuscript.

\section{REFERENCES}

1. Glezen P, Denny FW. Epidemiology of acute lower respiratory disease in children. N Engl 7 Med 1973;288:498-505.

2. Ray CG, Minnich LL, Holberg CJ, et al. Respiratory syncytial virus-associated lower respiratory illnesses: possible influ- 
ence of other agents. Pediatr Infect Dis 7 1993;12:15-9.

3. Pelletier AJ, Mansbach JM, Camargo CA. Direct medical costs of bronchiolitis hospitalizations in the United States. Pediatrics 2006;118:2418-23.

4. Welliver JR, Welliver RC. Bronchiolitis. Pediatr Rev 1993; 14:134-9.

5. Welliver TP, Garofalo RP, Hosakote Y, et al. Severe human lower respiratory tract illness caused by respiratory syncytial virus and influenza virus is characterized by the absence of pulmonary cytotoxic lymphocyte responses. J Infect Dis 2007; 195:1126-36

6. Johnson JE. The histopathology of fatal untreated human respiratory syncytial virus infection. Mod Pathol 2007;20:108-19.

7. Kuzik BA, Al Qadhi SA, Kent S, et al. Nebulized hypertonic saline in the treatment of viral bronchiolitis in infants. J Pediatr 2007;151:266-70.

8. Corneli HM, Zorc JJ, Mahajan P, et al. A multicenter, randomized, controlled trial of dexamethasone for bronchiolitis. NEngl 7 Med 2007;357:331-9.

9. American Academy of Pediatrics Subcommittee on the Diagnosis and Management of Bronchiolitis. Diagnosis and management of bronchiolitis. Pediatrics 2006;118:1774-93.

10. Yanney M, Vyas H. The treatment of bronchiolitis. Arch Dis Child 2008;93:793-8.

11. Sarrell EM, Tal G, Witzling M, et al. Nebulized 3\% hypertonic saline solution treatment in ambulatory children with viral bronchiolitis decreases symptoms. Chest 2002;122:2015-20.

12. Tal G, Cesar K, Oron A, et al. Hypertonic saline/epinephrine treatment in hospitalized infants with viral bronchiolitis reduces hospitalizations stay: 2 years experience. Isr Med Assoc J 2006;8:169-73.

13. Zhang L, Mendoza-Sassi RA, Wainwright C, et al. Nebulized hypertonic saline solution for acute bronchiolitis in infants. Cochrane Database Syst Rev 2008;CD006458.

14. Robinson M, Hemming AL, Regnis JA, et al. Effect of increasing doses of hypertonic saline on mucociliary clearance in patients with cystic fibrosis. Thorax 1997;52:900-3.

15. Tomooka LT, Murphy C, Davidson TM. Clinical study and literature review of nasal irrigation. Laryngoscope 2000;110: 1189-93.

16. Lowell DI, Lister G, VonKoss H, et al. Wheezing in infants: the response to epinephrine. Pediatrics 1987;79:939-45.

17. Amirav I, Balanov I, Gorenberg M, et al. Nebulizer hood compared to mask in wheezy infants: aerosol therapy without tears! Arch Dis Child 2003;88:719-23.
18. Ralston S, Hartenberger C, Anaya T, et al. Randomized, placebo-controlled trial of albuterol and epinephrine at equipotent beta- 2 agonist doses in acute bronchiolitis. Pediatr Pulmonol 2005;40:292-9.

19. Menon K, Sutcliffe T, Klassen TP. A randomized trial comparing the efficacy of epinephrine with salbutamol in the treatment of acute bronchiolitis. J Pediatr 1995;126:1004-7.

20. Williams PV. Inhalation bronchoprovocation in children. Immunol Allergy Clin North Am 1998;18:149-65.

21. Calogero C, Sly PD. Acute viral bronchiolitis: To treat or not to treat — that is the question. J Pediatr 2007;151:235-7.

22. Grewal S, Ali S, McConnell MD, et al. A randomized trial of nebulized 3\% hypertonic saline with epinephrine in the treatment of acute bronchiolitis in the emergency department. Arch Pediatr Adolesc Med 2009;163:1007-12.

23. Anil AB, Anil M, Saglam AB, et al. High volume normal saline alone is as effective as nebulized salbutamol-normal saline, epinephrine-normal saline, and 3\% saline in mild bronchiolitis. Pediatr Pulmonol 2010;45:41-7.

24. Plint AC, Johnson DW, Patel HM, et al. Epinephrine and dexamethasone in children with bronchiolitis. N Engl 7 Med 2009;360:2079-89.

25. Schuh S, Coates AL, Binnie R, et al. Efficacy of oral dexamethasone in outpatients with acute bronchiolitis. 7 Pediatr 2002;140:27-32.

26. Kellner JD, Ohlsson A, Gadomski AM, et al. Efficacy of bronchodilator therapy in bronchiolitis. Arch Pediatr Adolesc Med 1996;150:1166-72.

27. Gadomski AM, Bhasale AL. Bronchodilators for bronchiolitis. Cochrane Database Syst Rev 2006;3:CD001266.

28. Mansbach JM, Clark S, Christopher NC, et al. Prospective multicenter study of bronchiolitis: predicting safe discharges from the emergency department. Pediatrics 2008;121:680-8.

29. Brand PLP, Baraldi E, Bisgaard H, et al. Definition, assessment and treatment of wheezing disorders in preschool children: an evidence-based approach. Eur Respir 7 2008;32:1096-110.

30. Henderson J, Granell R, Heron J, et al. Associations of wheezing phenotypes in the first 6 years of life with atopy, lung function and airway responsiveness in mid-childhood. Thorax 2008;63:974-80.

31. Subbarao P, Balkovec S, Solomon M, et al. Pilot study of safety and tolerability of inhaled hypertonic saline in infants with cystic fibrosis. Pediatr Pulmonol 2007;42:471-6.

Correspondence to: Dr. Brian Kuzik, 208-1 Quarry Ridge Rd., Barrie ON L4M 7G1; briankuzik@hotmail.com 